\title{
Non-hispanic whites have higher risk for pulmonary impairment from pulmonary tuberculosis
}

\author{
Jotam G Pasipanodya ${ }^{1,2}$, Edgar Vecino ${ }^{1}$, Thaddeus L Miller ${ }^{1}$, Guadalupe Munguia', Gerry Drewyer ${ }^{4}$, \\ Michel Fernandez ${ }^{1,4}$, Philip Slocum ${ }^{3}$ and Stephen E Weis ${ }^{1,4^{*}}$
}

\begin{abstract}
Background: Disparities in outcomes associated with race and ethnicity are well documented for many diseases and patient populations. Tuberculosis (TB) disproportionately affects economically disadvantaged, racial and ethnic minority populations. Pulmonary impairment after tuberculosis (PIAT) contributes heavily to the societal burden of TB. Individual impacts associated with PIAT may vary by race/ethnicity or socioeconomic status.

Methods: We analyzed the pulmonary function of 320 prospectively identified patients with pulmonary tuberculosis who had completed at least 20 weeks standard anti-TB regimes by directly observed therapy. We compared frequency and severity of spirometry-defined PIAT in groups stratified by demographics, pulmonary risk factors, and race/ethnicity, and examined clinical correlates to pulmonary function deficits.

Results: Pulmonary impairment after tuberculosis was identified in $71 \%$ of non-Hispanic Whites, $58 \%$ of nonHispanic Blacks, $49 \%$ of Asians and 32\% of Hispanics $(p<0.001$ ). Predictors for PIAT varied between race/ethnicity. PIAT was evenly distributed across all levels of socioeconomic status suggesting that PIAT and socioeconomic status are not related. PIAT and its severity were significantly associated with abnormal chest $x$-ray, $p<0.0001$. There was no association between race/ethnicity and time to beginning TB treatment, $p=0.978$.

Conclusions: Despite controlling for cigarette smoking, socioeconomic status and time to beginning TB treatment, non-Hispanic White race/ethnicity remained an independent predictor for disproportionately frequent and severe pulmonary impairment after tuberculosis relative to other race/ethnic groups. Since race/ethnicity was self reported and that race is not a biological construct: these findings must be interpreted with caution. However, because race/ethnicity is a proxy for several other unmeasured host, pathogen or environment factors that may contribute to disparate health outcomes, these results are meant to suggest hypotheses for further research.
\end{abstract}

\section{Background}

Health outcome disparities associated with race and ethnicity are well documented for many diseases and patient populations. While there are a variety of explanations for these effects, they are not fully understood [1-3]. Socio-economic, biological, cultural, demographic, and other factors all contribute to an individual's health before, during and after illness $[1,2,4]$. While some contributors to health disparities are well defined the

\footnotetext{
* Correspondence: weistephen@me.com

'Department of Internal Medicine, UNT- Health Science Center at Fort Worth, Fort Worth, TX, USA

Full list of author information is available at the end of the article
}

contribution of biological and gender differences, personal behaviors, value choices, and race/ethnicity on specific diseases and their clinical outcomes are not $[1,3]$.

It is well established that tuberculosis (TB) is disproportionately prevalent among economically disadvantaged and racial/ethnic minority populations [5-8]. The health impacts of TB associated with differences in race, ethnicity, and more primary health risks are incompletely known [5-12]. In a prior study, we measured the frequency and degree of pulmonary impairment in $\mathrm{TB}$ patients who were treated with standard regimes delivered by directly observed therapy (DOT) [13]. Spirometry-defined pulmonary impairment after tuberculosis

\section{Biomed Central}


(PIAT) was found in a majority of the cohort, and was more common in US born and older patients $[13,14]$. The study's sample size did not allow stratified analysis of PIAT prevalence and severity between race/ethnic and other patient groups. We expanded our sample to allow a comparison of PIAT frequency across self-identified race/ethnicity groups and by socioeconomic status.

\section{Methods}

\section{Patients and setting}

This was a prospective cohort study of all patients 16 years of age and older receiving treatment for cultureconfirmed pulmonary tuberculosis at Tarrant County Public Health (TCPH) from July 2005 to December 2009. The population includes all persons with cultureconfirmed pulmonary tuberculosis in Tarrant County, some of whom also had concurrent extra-pulmonary tuberculosis. Texas requires all diagnosed TB cases be reported to the local public health authorities [15]. TCPH is the health authority for an urban county with a 2010 population of $1,789,900$ [15]. TCPH provides treatment for all persons with $\mathrm{TB}$ within this jurisdiction, using universal DOT delivered to the patient's preferred location $[15,16]$. All patients were treated with standard 4 drug American Thoracic Society (ATS) and Centers for Diseases and Prevention Control (CDC) recommended anti-TB regimens [17]. Patients who had completed at least 20 weeks of this treatment were asked to participate in this study of their pulmonary function. The Institutional Review Board of the University of North Texas Health Science Center at Fort Worth approved the study; IRB project \#24-109. All subjects gave written informed consent.

\section{Pulmonary function testing}

Pulmonary function tests (PFTs) by spirometry were performed on consenting patients. Spirometry was conducted according to ATS guidelines for maneuver, techniques and quality control using the Spirotouch device (Spirotouch Spirometry System 086578; Spacelabs Burdick; Deerfield, WI) $[18,19]$. Patients with a history of bronchodilator use received nebulized albuterol $15 \mathrm{~min}$ before the test. Consistent results were considered variation of $5 \%$ or less between measurements on three separate tests. The best of three consistent results was used to grade pulmonary function.

Impairment was defined and graded using American Medical Association (AMA) guides for evaluation of permanent impairments [20]. Forced Expiratory Volume in $1 \mathrm{~min}(\mathrm{FEV} 1)>=80 \%$, Forced Vital Capacity (FVC) $>=80 \%$ and FEV1/FVC $>70 \%$ of predicted were considered normal. Other results defined pulmonary impairment. Impairment was categorized as none, mild (if FEV1 or FVC was $>60 \%$ but $<80 \%$ ), moderate (if
FEV1 or FVC was $41 \%$ to $59 \%$ ) or severe (if FEV1 or FVC was $<40 \%$ ) using an interpretive algorithm from the AMA [18-20].

Trained research personnel obtained demographic data from patients at the time of enrolment using a standardized instrument. Data were double entered into a Microsoft Office 2003 ACCESS database (Microsoft Corporation, Redmond, WA. 98052). Subjects self-identified their race/ethnicity, and were given an option to identify themselves as Hispanic in accordance with US federal definitions [21]. Because of their small numbers we combined self-identified Pacific Islanders, Native American Indians, and Arabs into one group.

Socioeconomic status was assessed according to established methods [22,23] and included (1) highest level of education attained, (2) employment status at diagnosis, (3) self-identified occupation, and (4) estimate of household income. Education was categorized into quartiles of years < 12, 12, 12 to 15 and > 16 years. Similarly, areamedian household income, derived from census-tract ZIP codes of the patient's home address, was divided into quartiles of $<\$ 27,250, \$ 27,251$ to $\$ 37180, \$ 37,180$ to 52,777 and $>\$ 52,778$; ranges comparable to published data from US TB patients $[5,24]$. Homeless person who did not report income were treated as missing data. We scored patients' occupations using standard methods and correlated them to levels of education $[22,23,25]$. Occupational status was ranked according to prestige $[22,23,25]$. Education was then used as a proxy for socioeconomic status [23].

Time to beginning TB treatment, defined as the time from self-reported onset of symptoms to beginning tuberculosis therapy, was measured to give insight into patient-related factors associated with accessing healthcare [1]. Ever smokers were patients who gave a history of current or past cigarettes smoking. Lifetime volume of cigarette exposure was estimated using pack-years. Exposure to solid fuel smoke (biomass exposure) and duration of biomass exposure was compared between groups.

We correlated radiographic abnormality with pulmonary function using a validated scoring rubric derived from published sources (Table 1) [26]. An experienced physician (SEW) read the baseline chest $\mathrm{x}$-rays taken during therapy and follow-up chest $\mathrm{x}$-rays taken after 20 weeks of treatment. TB disease site was classified as "pulmonary only" or "both pulmonary and extra pulmonary. Observed abnormalities, cavitation, and infiltration were standardized and scored using the rubric. The summed total score was correlated with observed pulmonary function.

\section{Statistical analysis}

Parsimonious multivariate logistic regression models were constructed and analyzed for the full sample and 
Table 1 Rubric to standardize chest radiographic findings

\begin{tabular}{ll}
\hline Findings & Score \\
\hline Abnormal Appearance & 0 \\
\hline No & 1 \\
\hline Yes & 0 \\
\hline Cavitation & 1 \\
\hline None & 2 \\
\hline Cumulative diameter less than $2 \mathrm{~cm}$ & 3 \\
\hline Cumulative diameter 2 to $4 \mathrm{~cm}$ & 0 \\
\hline Cumulative diameter greater than $4 \mathrm{~cm}$ & 1 \\
\hline Extent and pattern of infiltrating lesions & 2 \\
\hline None & 3 \\
\hline Occupy less than 25\% of thoracic cavity & 1 \\
\hline Occupy 25 to $49 \%$ of thoracic cavity & \\
\hline Occupy more than $50 \%$ of thoracic cavity & \\
\hline Miliary pattern &
\end{tabular}

separately for US-born, foreign-born persons and each racial/ethnic group. Both age and smoking have been shown to independently exacerbate pulmonary function decline so were included in all multivariate models [27-29]. The median age at which impairment and moderate/severe impairment occurred among the racial/ethnic groups were compared using Kaplan-Meir methods. Comparison between groups was performed using Chi-Square or Fisher's exact tests and/or analysis of variance (ANOVA) plus the Kruskal-Wallis tests when appropriate. Analysis was performed using SPSS version 12 for Windows (SPSS Inc; Chicago, IL) and GraphPad Prism version 5 (GraphPad Software; La Jolla, CA).

\section{Results}

Between July 2005 and December 2009, 362 patients with culture confirmed pulmonary tuberculosis were reported to Tarrant County Health and were eligible for study enrolment (Figure 1). Of these, 320 (88\%) were enrolled. Sixty-nine (22\%) self-identified as non-Hispanic White, $85(27 \%)$ as non-Hispanic Black, $81(25 \%)$ as Asian, 82 (26\%) as Hispanic and $3(0.9 \%)$ were combined as "other" racial/ethnic group. The 3 subjects in the "other" racial/ethnic group were all male and included two with mild impairment and one nonimpaired and were excluded from further analysis.

TB disease type and site, and patients' access to TB care was similar between race/ethnicity (Table 2). There were significantly different demographic and clinical characteristics between race/ethnicity (Table 2). HIV infection was significantly higher among non-Hispanic Blacks and level of education significantly lower among Hispanics compared to non-Hispanic Whites. Clinical and demographic characteristics, including age and

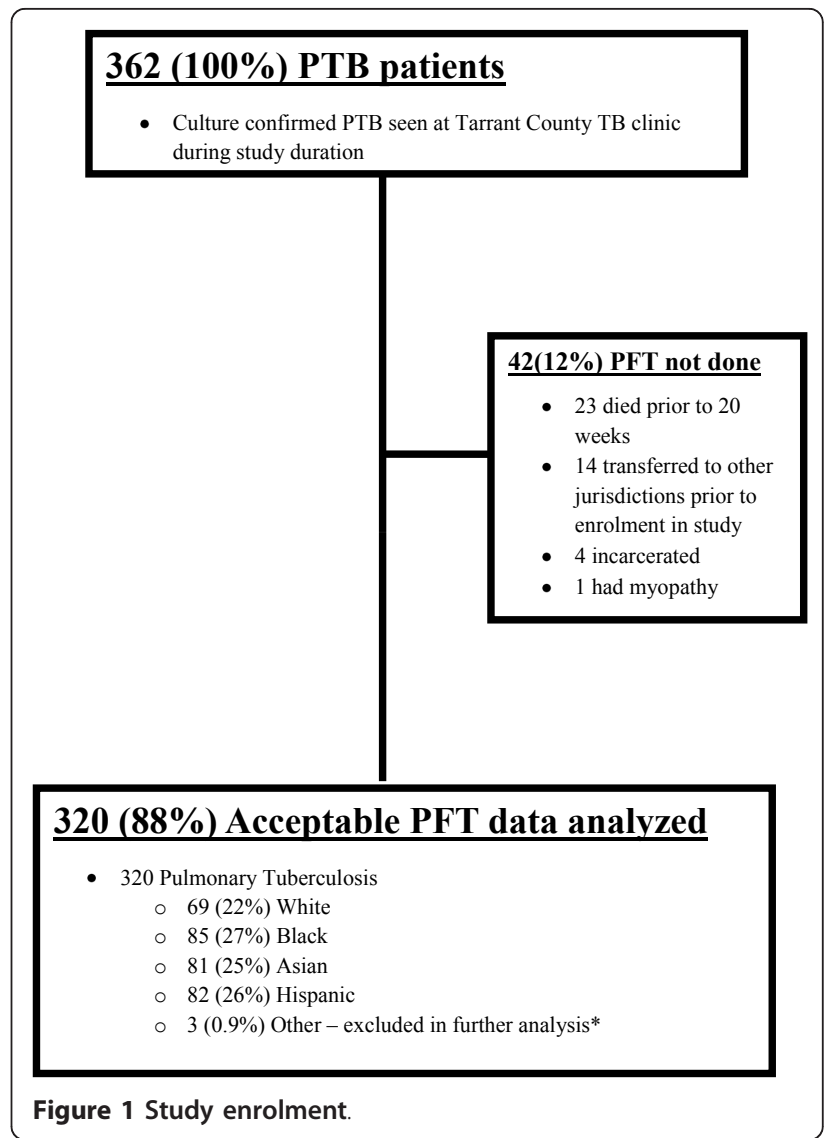

smoking of US-born were significantly different from those who were foreign-born. Both proportion of eversmokers and level of lifetime cigarette use was significantly higher among Whites $(p<0.001$ for both measures) than other groups (Table 2).

The distribution of pulmonary impairment after tuberculosis (PIAT) and its severity among racial/ethnic groups, by smoking status and by socioeconomic status is shown in Figures 2, 3, and 4, respectively. PIAT was more frequent among non-Hispanic Whites compared to other race/ethnic groups $(p<0.001)$, and was more severe $(p=0.001)$ (Figure 2). Pulmonary impairment was identified in $71 \%$ of non-Hispanic Whites, $58 \%$ of non-Hispanic Blacks, $49 \%$ of Asians and 32\% of Hispanics. PIAT frequency was significantly higher among non-Hispanic Whites compared to other racial/ethnic groups in both ever-smokers and never-smokers, $(p<$ 0.0001) (Figure 3).

The distribution of employment, income, occupation, and education data among subjects was similar to that reported for other US TB patients (9-11). Education and income were significantly correlated (Pearson's correlation coefficient $(\mathrm{r})=0.21, p<0.001)$. When occupational status was ranked according to prestige, it also significantly correlated with both education and income 
Table 2 Demographic and clinical characteristics of 317 patients with pulmonary tuberculosis (TB) included in the analysis

\begin{tabular}{|c|c|c|c|c|c|}
\hline & Non-Hispanic White & Non-Hispanic Black & Asian & Hispanic & \\
\hline & $\mathrm{n}=69$ & $\mathrm{n}=85$ & $\mathrm{n}=82$ & $\mathrm{n}=81$ & p-value \\
\hline \multicolumn{6}{|l|}{ Demography } \\
\hline Male & $58(84)$ & $54(64)$ & $58(71)$ & $52(64)$ & 0.023 \\
\hline US-born & $66(96)$ & $62(73)$ & $4(5)$ & $11(4)$ & $<0.001$ \\
\hline Foreign-born & $3(4)$ & $23(27)$ & $78(95)$ & $70(86)$ & \\
\hline Age (mean[SD]) years & $54.33(13.10)$ & $43.71(13.51)$ & $44.91(16.61)$ & $45.95(15.81)$ & $<0.001$ \\
\hline \multicolumn{6}{|l|}{ Clinical } \\
\hline HIV positive & $5(7)$ & $15(18)$ & $3(4)$ & $7(9)$ & 0.052 \\
\hline Ever-Smokers n(\%) & $56(81)$ & $44(52)$ & $35(43)$ & $39(48)$ & $<0.001$ \\
\hline Smoking volume(mean[SD]) pack-years & $32.68(39.56)$ & $8.19(15.48)$ & $5.52(9.50)$ & $4.67(11.78)$ & $<0.001$ \\
\hline \multicolumn{6}{|l|}{ Biomass Smoke } \\
\hline Exposed n (\%) & $5(9)$ & $10(15)$ & $29(45)$ & $28(38)$ & 0.001 \\
\hline \multicolumn{6}{|l|}{ Biomass Smoke Exposure duration } \\
\hline (mean $[S D]$ ) years & $0.80(3.26)$ & $2.52(7.38)$ & $6.94(12.54)$ & $7.09(14.27)$ & 0.001 \\
\hline FVC (\% predicted [SD]) & $77.54(23.70)$ & $78.69(19.05)$ & 82.09 (19.10) & 90.15 (21.19) & 0.001 \\
\hline FEV1 (\% predicted[SD]) & $71.12(24.30)$ & $76.98(22.69)$ & $82.85(19.54)$ & $91.83(23.03)$ & $<0.001$ \\
\hline FEV1/FVC (\% [SD]) & $73.13(13.48)$ & $81.11(13.35)$ & $84.01(9.75)$ & $85.26(10.01)$ & $<0.001$ \\
\hline BMI (mean[SD]) & $21.23(5.24)$ & $23.07(4.58)$ & $22.32(4.90)$ & $25.08(8.62)$ & $<0.001$ \\
\hline \multicolumn{6}{|l|}{ Disease site and pattern } \\
\hline PTB only & $66(96)$ & $75(88)$ & $76(93)$ & $75(93)$ & 0.39 \\
\hline PTB and EPTB & $3(4)$ & $10(12)$ & $6(7)$ & $6(7)$ & \\
\hline \multicolumn{6}{|l|}{ Pattern of Impairment } \\
\hline Restrictive & $33(68)$ & $34(69)$ & $30(75)$ & $21(81)$ & 0.571 \\
\hline Obstructive & $8(16)$ & $4(8)$ & $3(8)$ & $3(11)$ & \\
\hline Mixed & $8(16)$ & $11(23)$ & $7(17)$ & $2(8)$ & \\
\hline Access (median [IQR]) Days to Begin TB Treatment & $63(183)$ & $65(130)$ & $93(157)$ & $80(103)$ & 0.978 \\
\hline
\end{tabular}

$(\mathrm{r}=0.33, p<0.001$ and $\mathrm{r}=0.15, p=0.005$, respectively). PIAT prevalence was evenly distributed across all levels of socioeconomic status: when the highest level of education attained was used as a proxy for socioeconomic status (Figure 4).

The median "time to beginning TB treatment" for non-impaired persons was 62 days (interquartile range [IQR] was 12-110); 93 days for mildly impaired persons (IQR 61-110), 138 days for moderately impaired subjects (IQR 32-271), and 37 days for severely impaired subjects (IQR 12-60). There was no significant association between race/ethnicity and time to beginning TB treatment, $(\mathrm{p}=0.978)$ (Table 2$)$. Similarly, no association between time to beginning treatment and PIAT was observed ( $\mathrm{p}=0.058$ ) (data not shown).

We obtained baseline chest $\mathrm{x}$-ray results for $99 \%$ of subjects $(n=314)$, and for $90 \%(n=254)$ of subjects after either 20 weeks or at therapy completion. Pulmonary impairment was significantly $(p<0.001)$ correlated with the presence and magnitude of abnormal chest $\mathrm{x}$ ray findings for both baseline (Spearman's correlation coefficient $(r)=0.4)$, and subsequent readings, $(r=$ 0.42). Figure 5 shows the distribution of a standardized severity index among subjects with pulmonary impairment identified by spirometry.

In univariate analysis race/ethnicity, age and US-birth were significantly associated with PIAT (Table 3). The likelihood of PIAT increased by $2 \%$ (95\% confidence interval $[\mathrm{CI}] 1,3)$ for each 1 year increase in age. PIAT was 2.3 times more common (95\% CI 1.46, 3.61) in USborn than foreign-born subjects. Race/ethnic groups and foreign birth were correlated: Spearman's $\mathrm{r}=0.69, p<$ 0.001 .

In a multivariate analysis that controlled for potential demographic and clinical confounders; the only significant predictor for PIAT was non-Hispanic White race/ ethnicity, among whom PIAT prevalence was 3 times greater (95\% C.I. 1.18, 8.40). Since race/ethnic group and foreign birth were significantly correlated, and to avoid confounding, separate multivariate regression models were constructed and are shown in Tables 4 and 5. Risk factors for impairment were variable between 


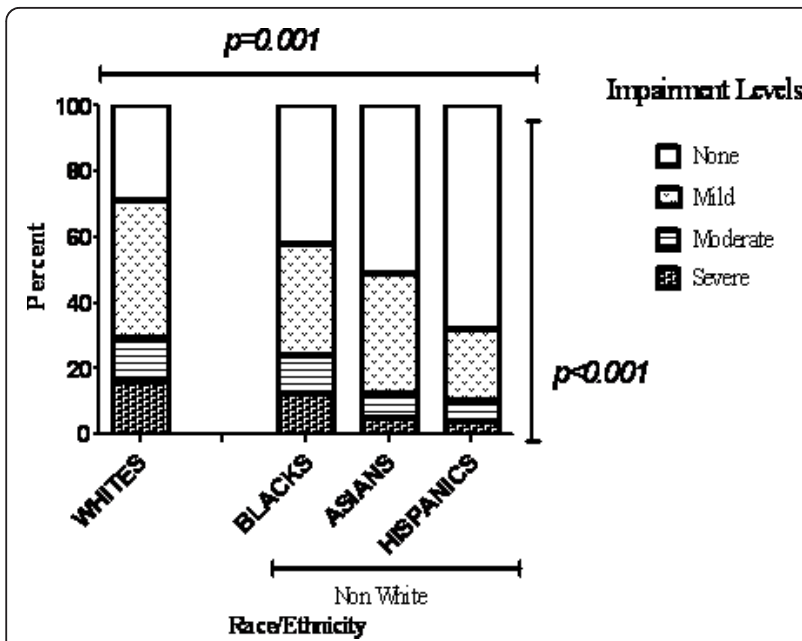

Figure $\mathbf{2}$ Comparisons of frequency and severity of pulmonary impairment between 317 self-identified racial and ethnic groups comprising 69 non-Hispanic Whites, 85 non-Hispanic Blacks, 82 Asians and $\mathbf{8 1}$ Hispanics. Figure 2 demonstrates that proportions impaired and the severity of impairment significantly varies between racial/ethnic groups; specifically both impairment frequency and severity was significantly higher among Whites compared to non-Whites.

race/ethnicity, with age independently predicting impairment in non-Hispanic Whites and non-Hispanic Blacks (Table 4). Smoking was associated with three fold (95\% CI $1.15,7.85$ ) increased risk for impairment among Asians, but was not predictive for impairment among non-Hispanic Whites (Table 4, Figure 3). Table 5 shows the multivariate regression model containing age, smoking and race/ethnicity of 144 US-born persons. In the model, only non-Hispanic White race/ethnicity and age

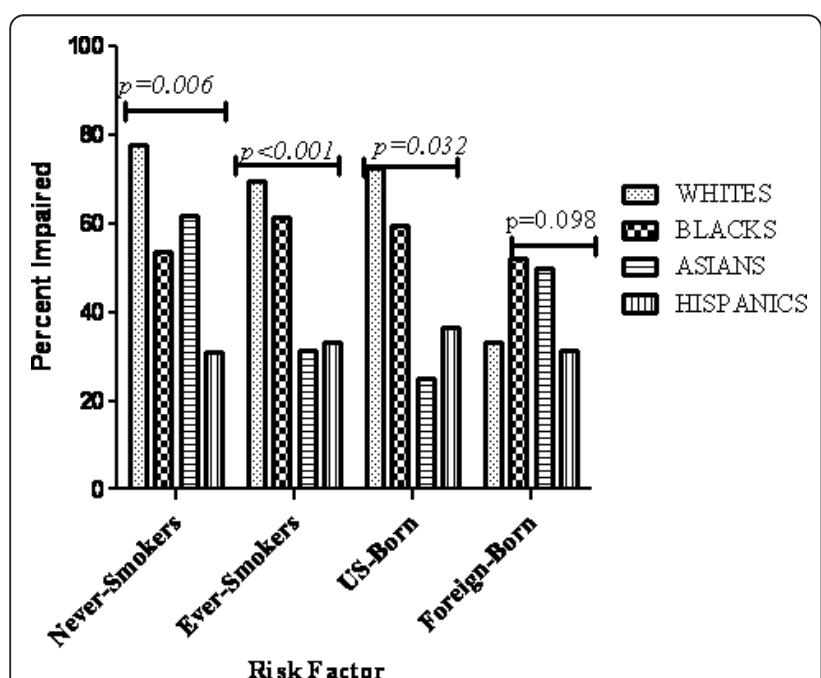

Figure 3 Comparison of the frequency of pulmonary impairment among all self-identified racial groups by country of birth and smoking status.

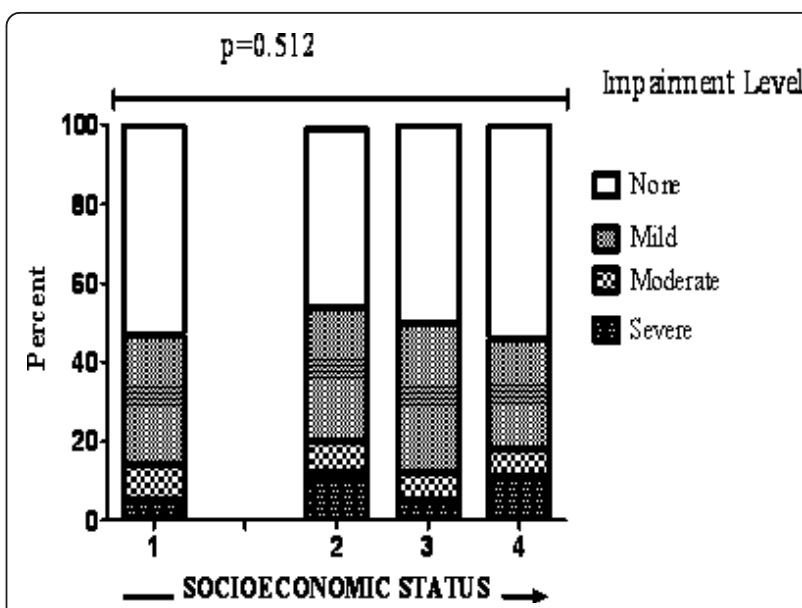

Figure 4 Comparisons of the frequency and severity of pulmonary impairment among patient with different socioeconomic status. Figure 4 shows that proportions impaired and the severity of impairment does not vary with increase in socioeconomic status.

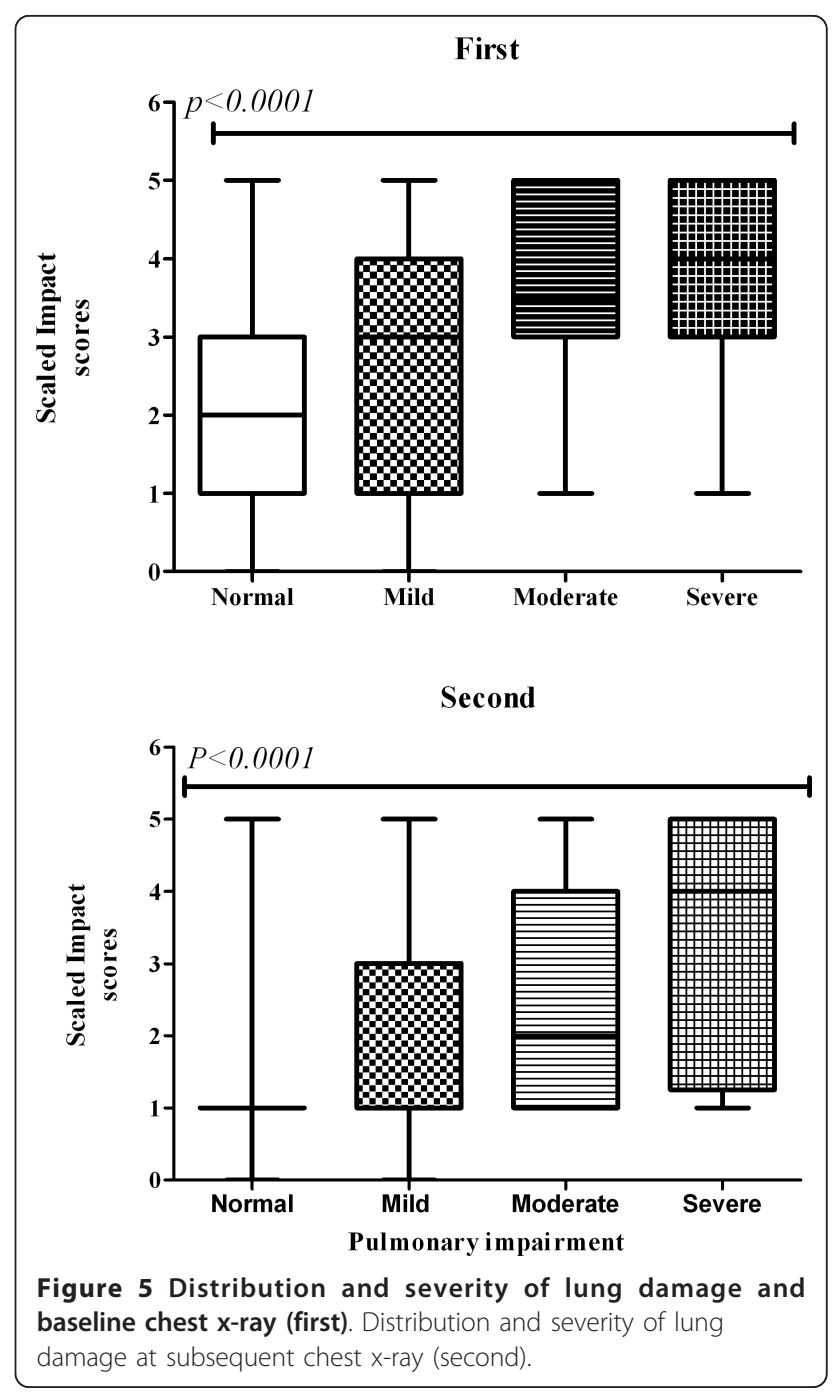


Table 3 Unadjusted odds ratio for some pulmonary impairment

\begin{tabular}{|c|c|c|}
\hline & OR (95\% C.I) & $p$-value \\
\hline Race & & $<0.001$ \\
\hline Whites & $5.18(2.58,10.42)$ & \\
\hline Blacks & $2.88(1.53,5.43)$ & \\
\hline Asian & $2.02(1.07,3.81)$ & \\
\hline Hispanics (reference) & $* *$ & \\
\hline \multicolumn{3}{|l|}{ Access } \\
\hline \multicolumn{3}{|l|}{ Days to Begin TB treatment } \\
\hline (days) & $1.00(1.00,1.01)$ & 0.098 \\
\hline \multicolumn{3}{|l|}{ Demographic and clinical characteristics } \\
\hline Male & $1.36(0.84,2.21)$ & 0.207 \\
\hline \multicolumn{3}{|l|}{ Females (reference)* } \\
\hline US-born & $2.30(1.46,3.61)$ & $<0.001$ \\
\hline \multicolumn{3}{|l|}{ Foreign-born(reference) $)^{*}$} \\
\hline Ever-Smokers & $1.00(0.64,1.56)$ & 0.997 \\
\hline \multicolumn{3}{|l|}{ Never-Smokers (reference) ${ }^{*}$} \\
\hline Biomass Smoke Exposure & $1.33(0.77,2.28)$ & 0.308 \\
\hline \multicolumn{3}{|l|}{ No Biomass Smoke Exposure (reference) ${ }^{*}$} \\
\hline Smoking Volume (pack-year) & $1.01(1.00,1.03)$ & 0.007 \\
\hline Age (years) & $1.02(1.01,1.03)$ & 0.031 \\
\hline BMl $(\mathrm{kg} / \mathrm{m} 2)$ & $0.97(0.93,1.01)$ & 0.087 \\
\hline \multicolumn{3}{|l|}{ Socioeconomic Status } \\
\hline \multicolumn{3}{|l|}{ Education } \\
\hline Some Education (< 12 years)(reference) $)^{*}$ & $* *$ & 0.470 \\
\hline High School Graduate (12 years) & $1.46(0.86,2.49)$ & \\
\hline Some College (13 - 15 years) & $1.33(0.67,2.64)$ & \\
\hline College Graduate ( 16 or more year) & $1.33(0.64,2.78)$ & \\
\hline \multicolumn{3}{|l|}{ Occupation } \\
\hline 1 (most prestigious) & $* *$ & 0.411 \\
\hline 2 & $1.17(0.52,2.67)$ & \\
\hline 3 & $1.68(0.90,3.14)$ & \\
\hline 4 (least prestigious) & $1.41(0.78,2.56)$ & \\
\hline \multicolumn{3}{|l|}{ Area-median household income } \\
\hline < US\$27 270 (reference) & $* *$ & 0.408 \\
\hline US\$27 $271-37180$ & $0.82(0.46,1.46)$ & \\
\hline US\$37 $181-52777$ & $0.76(0.40,1.44)$ & \\
\hline US\$52 777 & $1.55(0.82,2.92)$ & \\
\hline
\end{tabular}

$B M I$ body mass index $\left(\mathrm{kg} / \mathrm{m}^{2}\right)$; $O R$ odds ratio; $\mathrm{Cl}$ confidence interval
Table 5 Predictors for pulmonary impairment in 144 USborn patients with pulmonary tuberculosis

\begin{tabular}{lcr}
\hline & OR $(\mathbf{9 5} \% \mathbf{C l})$ & P-value \\
\hline Age (years) & $1.05(1.02,1.08)$ & 0.001 \\
Ever-Smokers* & $1.77(0.73,4.29)$ & 0.208 \\
Non-Hispanic Whites ${ }^{*}$ & $4.94(1.13,21.63)$ & 0.034 \\
Non-Hispanic Blacks ${ }^{+}$ & $3.51(0.81,15.12)$ & 0.093 \\
Asians ${ }^{\text {Constant }}$ & $0.95(0.05,18.57)$ & 0.971 \\
\hline
\end{tabular}

Comparison groups; *Ever-Smokers versus Never-Smokers; † Hispanics; $O R$ odds ratio; $\mathrm{Cl}$ confidence interval; The patients whose race/ethnicity was designated 'other' are excluded in this analysis

independently predict PIAT. The age-related risk for PIAT increased 5\% (95CI 2.0, 8.1) per year of age.

Onset of age-related lung function decline is variable $[19,30,31]$; however, for this study cohort onset of impairment was related to the age at which the different race/ethnic groups acquired tuberculosis. Consequently, the risk for moderate or severe pulmonary impairment is significantly higher among older Whites compared with non-Whites. As an example, the median age was 51 years for non-Hispanic Blacks, 59 for Whites, 56 for Asians and 71 years for Hispanics (Figure 6). Similarly, the probability for developing moderate to severe impairment was higher in non-Hispanic Blacks of younger age groups compared to other race/ethnic groups (Figure 6, panel B). The median age for non-Hispanic Blacks was 63 and that for non-Hispanic Whites was $72, p=0.0239$. The hazard ratio [HR] was 0.45 $(0.22,0.90)$.

\section{Discussion}

In the U.S., racial/ethnic minorities and foreign-born persons face disparate risks for TB infection and higher levels of poor TB disease outcomes, including mortality [5-9]. We analyzed the relationship between race/ethnicity and PIAT in a cohort with culture-confirmed pulmonary tuberculosis that had completed a minimum of 20 weeks of therapy. We found that self-identified nonHispanic White TB patients had disproportionately more frequent and severe pulmonary impairment

Table 4 Predictors for pulmonary impairment in all 69 Whites, 85 Blacks, 82 Asians and 81 Hispanics with pulmonary tuberculosis

\begin{tabular}{lcccc}
\hline & Non-Hispanic Whites & Non-Hispanic Blacks & Asians & Hispanics \\
\hline Age (years) & $1.06(1.01,1.11)^{*}$ & $1.04(1.00,1.08)^{*}$ & $0.98(0.95,1.01)$ & $1.02(0.99,1.05)$ \\
US-born † & $27.89(1.02,766.08)^{*}$ & $0.98(0.31,3.06)$ & $0.28(0.03,3.08)$ & $1.07(0.27,4.17)$ \\
Ever Smokers $\neq$ & $2.68(0.48,14.98)$ & $1.09(0.38,3.11)$ & $3.0(1.15,7.85)^{*}$ & $1.02(0.39,2.64)$ \\
Cox \& Snell R-Square & 0.12 & 0.06 & 0.12 & 0.02 \\
Chi-Square (p-value) & 0.029 & 0.156 & 0.018 & 0.624 \\
\hline
\end{tabular}

${ }^{*} p<0.05 ;+$ Reference $=$ Foreign-born; $\neq$ Reference $=$ Never Smokers; $O R$ odds ratio; $\mathrm{Cl}$ confidence interval 


\section{Pand A}

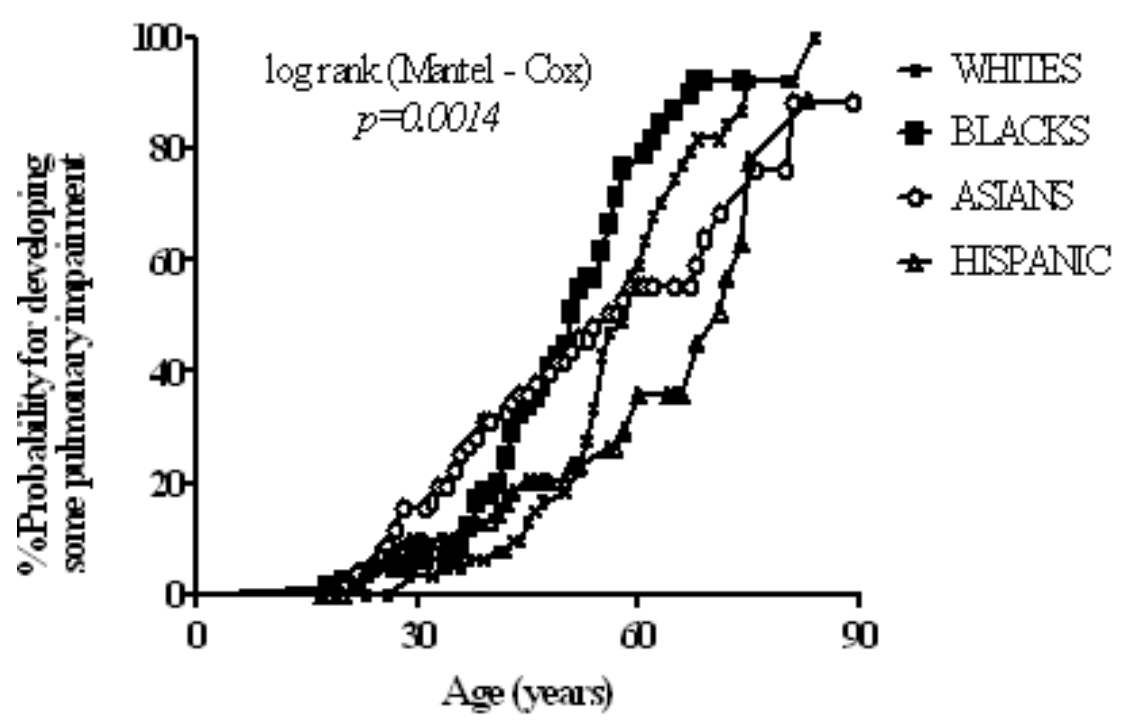

\section{Pand B}

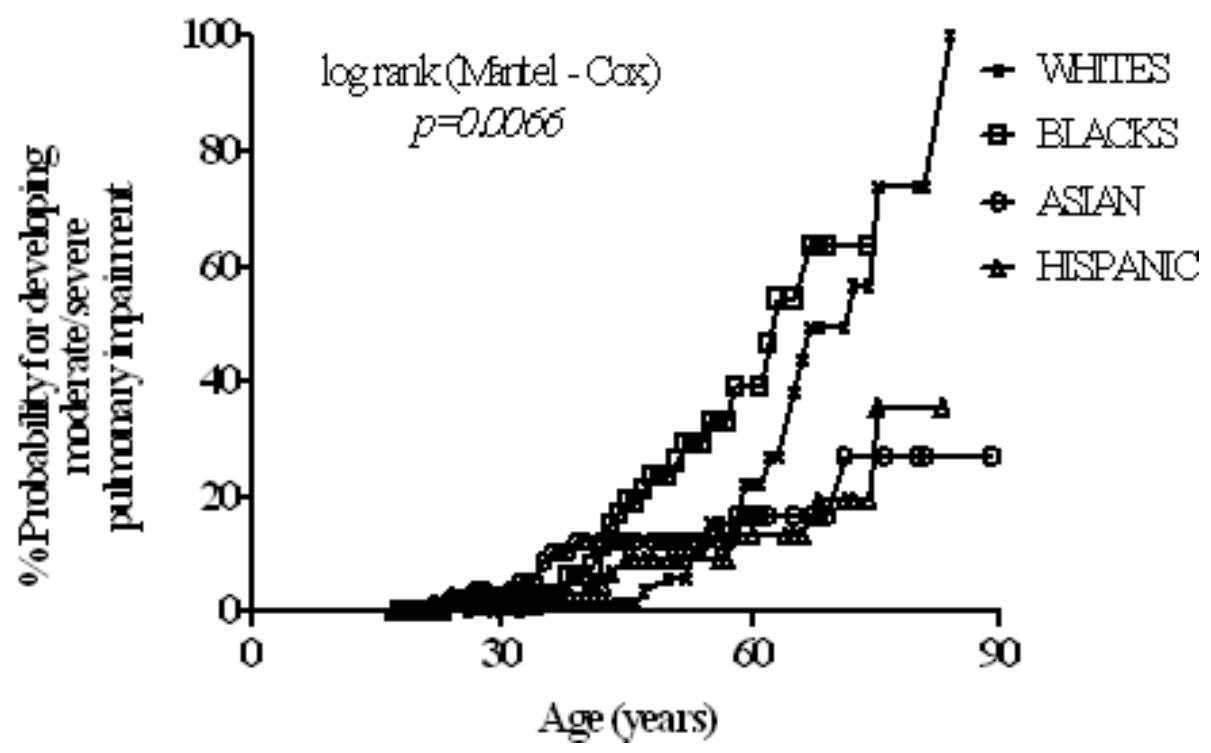

Figure 6 Hazard ratios for different racial groups in developing some pulmonary impairment (Panel A.) and moderate or severe pulmonary impairment (Panel B) with increase in age. The median ages for panel A are; non-Hispanic Whites 58 years, non-Hispanic Blacks 51 years, Asians 57 years and Hispanics 68 years. For panel B the median age for non-Hispanic Whites is 72 and that for non-Hispanic Blacks is 63.

relative to other race/ethnicities $(72 \%$ vs. $48 \%)$, odds ratio (OR) of 3.15. These differences persist despite control for the effects of age, body mass index, smoking, access to medical treatment, foreign birth and socio-economic status. Among the potential explanatory variables analyzed, only age and race/ethnicity were significant predictors for impairment in US born persons. These data demonstrate a previously unrecognized disparate negative health impact to specific populations of $\mathrm{TB}$ patients.

Current U.S. policy does not consider older adults high-priority candidates for testing and treatment of 
LTBI unless they have specific risks for developing TB disease $[17,32]$. These recommendations are based on the potential for adverse drug events associated with LTBI treatment. Predictors for PIAT varied between race/ethnic groups and by country of birth. We found the likelihood for PIAT to increases by an average 5\% for each additional increase in age for US-born patients (Table 5; Figure 6). NHANES data showed that poorer lung function is also associated with poor clinical outcomes including premature death $[30,33]$. This together with our findings suggests that moderate to severe PIAT may also be associated with earlier mortality. Future versions of LTBI treatment guidelines should consider reduction of tuberculosis burden from preventing PIAT as an additional treatment benefit.

Cigarette smoking, an established cause of pulmonary impairment, was significantly more prevalent among non-Hispanic Whites compared to other racial/ethnic groups. The proportion of non-Hispanic Whites impaired among never-smokers was $70 \%$ compared to $78 \%$ among ever-smokers. PIAT was more frequently encountered among non-Hispanic Whites compared to other $\mathrm{racial} / \mathrm{ethnic}$ groups $(p<0.001)$, and when encountered was more likely to be severe $(\mathrm{p}=0.001)$ (Figure 2) even after controlling for age and smoking (Figure 3, Tables 4). While there were more non-Hispanic Whites who smoked our data shows this difference is not sufficient to explain the more severe impairment found in non-Hispanic Whites.

Previous studies have investigated pulmonary sequelae of TB from a number of perspectives, but these are not readily generalized to US populations [31,34-37]. Poh et al evaluated patients hospitalized for treatment with non-rifampin chemotherapy regimens and identified older age, disease severity at presentation and heavy smoking as predictors for pulmonary impairment [36]. A population-based study from Latin America demonstrated that older age and repeated TB disease were associated with pulmonary impairment [31]. Two South African studies of patients receiving inpatient treatment $[34,37]$ similarly demonstrated that repeated TB disease significantly increased risks for pulmonary impairment. Race/ethnicity was not explored in these studies $[31,34,37$. Despite management with best currently available therapy for tuberculosis we identified some PIAT in over half (52\%) of patients and severe PIAT, in which less than $50 \%$ of personal lung function remains, in almost 1 in 10 patients (9\%). Prevalence and severity of PIAT were not associated with diagnostic or treatment delay, suggesting that it occurs early among those with TB. Therefore, strategies to mitigate PIAT must primarily rely on prevention of active TB.

Our study failed to detect association between socioeconomic status and pulmonary impairment. This was an unexpected and novel finding. Poorer health outcomes are consistently associated with low socioeconomic status $[1,5,23]$. Despite Hispanics' lower socioeconomic status in our study cohort, and their higher TB incidence rates relative to other racial/ethnic groups in the US [5]; they enjoyed apparent protection against pulmonary impairment compared to other racial/ethnic groups. This finding supports what has been called the "healthy Hispanic Paradox," in which Hispanics experience disproportionately greater life expectancy relative to other racial/ethnic groups [38,39]. Equity in health care access within the study area allowed by the public treatment of TB may explain health outcomes' independence from socioeconomic status.

There are several areas within our study vulnerable to ascertainment bias: such as the fact that race/ethnicity was self-reported, identification and grading of pulmonary impairment was biased towards an obstructive pattern and that the chest $\mathrm{x}$-ray grading of impairment lacks consensus of standardization. Both race and ethnicity are contextual, mutually contradictory and usually assume socially defined constructs with no biologic basis such that even the definitions used by U.S. federal agencies change with every 10-year census [2,40]. Even though mixed race/ethnicity is rare among self-identified non-Hispanic Whites, the US Hispanic population has a heterogeneous ethnic ancestry comprising of American Indian, European and African origins [41]. In addition, $30 \%$ of self-identified US-born Blacks consider themselves of mixed race $[41,42]$. As a result, the true effects of race/ethnicity on health outcomes may be difficult to clearly distinguish and are subject to confounding. Indeed, AMA grading is biased towards impairment that is obstructive in nature; hence patients with restrictive patterns might be under-represented in these estimates [18-20]. Given these limitations, it cannot be excluded that the findings reflect different phenotypic disease entities among different groups, of which some might be influenced by smoking and some not.

\section{Conclusion}

In conclusion, we found that pulmonary TB patients, who self-identified as non-Hispanic White, had more prevalent and more severe pulmonary impairment. The risk for pulmonary impairment remained after several factors such as smoking and socioeconomic status were controlled. Since race/ethnicity was self reported and race is not a biological construct, these findings must be interpreted with caution. However, because since race/ ethnicity is a proxy for several other unmeasured host, pathogen or environment factors that may contribute to disparate health outcomes, these results are meant to suggest hypotheses for further research. Nevertheless, if these findings are confirmed among other populations 
in other locations, they suggest that the decision-making thresholds of risk of TB prevention strategies should be reconsidered to include the benefits of preventing PIAT.

\section{Acknowledgements}

This study could not have been completed without the TCPHD supplying study resources. We are indebted to the study participants whose participation made this study possible. We also are indebted to the Tuberculosis Epidemiologic Studies Consortium (TBESC) at the Centers for Disease Control and Prevention and to the Tuberculosis Trials Consortium (TBTC), which provided salary support for Drs. Pasipanodya, Munguia, Vecino, Weis, Miller, and Ms. Drewyer, although neither consortium directly funded this study, nor had any role in study design, data collection, data analysis, data interpretation, or writing of the report.

\section{Author details}

${ }^{1}$ Department of Internal Medicine, UNT- Health Science Center at Fort Worth, Fort Worth, TX, USA. ²Department of Internal Medicine, Division of Infectious diseases, UT Southwestern Medical Center at Dallas, Dallas, Texas, USA. ${ }^{3}$ Department of Internal Medicine, A.T. Still University of Health Sciences, Kirksville, MO, USA. ${ }^{4}$ Tarrant County Public Health Department, Division of TB Elimination, 1101 S. Main Street, Fort Worth, TX, USA.

\section{Authors' contributions}

Conception and designing of the study was done by JGP, PS, GD, and SEW. EV, GM, TM, GD, MF and SEW collected the data, while JGP, PS, TM and SEW analyzed the data. All authors wrote the manuscript. All authors read and approved the final manuscript.

\section{Competing interests}

The authors declare that they have no competing interests.

Received: 18 May 2011 Accepted: 10 February 2012

Published: 10 February 2012

\section{References}

1. Agency for Healthcare Research and Quality RM: National Healthcare Disparities Report; 2006. 2010 [http://www.ahrq.gov/qual/nhdr06/nhdr06. htm].

2. Sankar P, Cho MK, Condit CM, Hunt LM, Koenig B, Marshall P, et al: Genetic research and health disparities. JAMA 2004, 291:2985-2989.

3. U.S.Department of Health and Human Services, Washington D: Healthy people 2010. understanding and improving health and objectives for improving health. U.S. Government Printing Office 2 2010.

4. Settle K, Posner MR, Schumaker LM, Tan M, Suntharalingam M, Goloubeva O, et al: Racial survival disparity in head and neck cancer results from low prevalence of human papillomavirus infection in black oropharyngeal cancer patients. Cancer Prev Res (Phila) 2009, 2:776-781.

5. Cantwell MF, McKenna MT, McCray E, Onorato IM: Tuberculosis and race/ ethnicity in the United States: impact of socioeconomic status. Am J Respir Crit Care Med 1998, 157:1016-1020.

6. Schneider E: Tuberculosis among American Indians and Alaska Natives in the United States, 1993-2002. Am J Public Health 2005, 95:873-880.

7. Schneider $E$, Moore M, Castro KG: Epidemiology of tuberculosis in the United States. Clin Chest Med 2005, 26:183-95, v.

8. Serpa JA, Teeter LD, Musser JM, Graviss EA: Tuberculosis disparity between US-born blacks and whites, Houston, Texas, USA. Emerg Infect Dis 2009, 15:899-904.

9. Hinman AR: Disease prevention program for racial and ethnic minorities. Ann Epidemiol 1993, 3:185-192.

10. Pasipanodya JG, Miller TL, Vecino M, Munguia G, Bae S, Drewyer G, Weis SE: Using the St. George respiratory questionnaire to ascertain health quality in persons with treated pulmonary tuberculosis. Chest 2007, 132(5):1591-1598.

11. Miller TL, McNabb SJ, Hilsenrath P, Pasipanodya J, Weis SE: Personal and societal health quality lost to tuberculosis. PLoS One 2009, 4:e5080.

12. Miller TL, McNabb SJ, Hilsenrath P, Pasipanodya J, Drewyer G, Weis SE: The societal cost of tuberculosis: Tarrant County, Texas, 2002. Ann Epidemiol 2010, 20:1-7.
13. Pasipanodya JG, Miller TL, Vecino M, Munguia G, Garmon R, Bae S, et al: Pulmonary impairment after tuberculosis. Chest 2007, 131:1817-1824.

14. Pasipanodya JG, McNabb SJ, Hilsenrath P, Bae S, Lykens K, Vecino E, et al: Pulmonary impairment after tuberculosis and its contribution to TB burden. BMC Publ Health 2010, 10:259.

15. Tarrant County Public Health Department., Division of Tuberculosis Elimination. Tarrant County Public Health, Client Services: 2010

16. Weis $S E$, Slocum PC, Blais FX, King B, Nunn M, Matney GB, et al: The effect of directly observed therapy on the rates of drug resistance and relapse in tuberculosis. N Engl J Med 1994, 330:1179-1184.

17. Blumberg HM, Burman WJ, Chaisson RE, Daley CL, Etkind SC, Friedman LN, et al: American thoracic society/centers for disease control and prevention/infectious diseases society of America: treatment of tuberculosis. Am J Respir Crit Care Med 2003, 167:603-662.

18. Miller MR, Hankinson J, Brusasco V, Burgos F, Casaburi R, Coates A, et al: Standardisation of spirometry. Eur Respir J 2005, 26:319-338.

19. Miller MR, Crapo R, Hankinson J, Brusasco V, Burgos F, Casaburi R, et al: General considerations for lung function testing. Eur Respir J 2005, 26:153-161.

20. Cocchiarella L, Andersson GBJ: The respiratory system. In Guides to the Evaluation of Permanent Impairment.. 5 edition. Edited by: Cocchiarella L, Andersson GBJ. Chicago: AMA Press; 2000:

21. Office of Management and Budget: Revisions to the standards for the classification of federal data on race and ethnicity. 1997, 62:58782-58790.

22. Bureau of Labor Statistics: Occupational classification system manual. 1998.

23. Duncan O: A socioeconomic index for all occupations. In Occupations and Social Status. Edited by: Reiss A Jr. New York: Free Press; 1961:109-138.

24. U.S.Census Bureau, State and County QuickFacts, State \& County QuickFacts, US Census Bureau Population Estimates, Census of Population and Housing, Small Area Income and Poverty Estimates, State and County Housing Unit Estimates, County Business Patterns, Nonemployer Statistics, Economic Census, Survey of Business Owners, Building Permits: Consolidated Federal Funds Report 2010, 5-26-2010

25. Shavers VL: Measurement of socioeconomic status in health disparities research. J Natl Med Assoc 2007, 99:1013-1023.

26. Simon G: Radiology in epidemiological studies and some therapeutic trials. Br Med J (Clin Res Ed) 1966, 2:491-494.

27. Alexeeff SE, Litonjua AA, Sparrow D, Vokonas PS, Schwartz J: Statin use reduces decline in lung function: VA normative aging study. Am J Respir Crit Care Med 2007, 176:742-747.

28. Hassmiller KM: The association between smoking and tuberculosis. Salud Publica Mex 2006, 48:(Suppl 1):S201-S216.

29. Kerstjens HA, Rijcken B, Schouten JP, Postma DS: Decline of FEV1 by age and smoking status: facts, figures, and fallacies. Thorax 1997, 52:820-827.

30. Mannino DM, Buist AS, Petty TL, Enright PL, Redd SC: Lung function and mortality in the United States: data from the First National Health and Nutrition Examination Survey follow up study. Thorax 2003, 58:388-393.

31. Menezes AM, Hallal PC, Perez-Padilla R, Jardim JR, Muino A, Lopez MV, et al: Tuberculosis and airflow obstruction: evidence from the PLATINO study in Latin America. Eur Respir J 2007, 30:1180-1185.

32. Blumberg HM, Leonard MK Jr, Jasmer RM: Update on the treatment of tuberculosis and latent tuberculosis infection. JAMA 2005, 293:2776-2784.

33. Neas LM, Schwartz J: Pulmonary function levels as predictors of mortality in a national sample of US adults. Am J Epidemiol 1998, 147:1011-1018.

34. Chronic pulmonary function impairment caused by initial and recurrent pulmonary tuberculosis following treatment. In Thorax Edited by: Eva Hnizdo TSGC 2000, 55:32-38.

35. Long R, Maycher B, Dhar A, Manfreda J, Hershfield E, Anthonisen N: Pulmonary tuberculosis treated with directly observed therapy: serial changes in lung structure and function. Chest 1998, 113:933-943.

36. Poh SC: Airway obstruction in patients with treated pulmonary tuberculosis. Singapore Med J 1975, 16:43-47.

37. Willcox PA, Ferguson AD: Chronic obstructive airways disease following treated pulmonary tuberculosis. Respir Med 1989, 83:195-198.

38. Lin CC, Rogot E, Johnson NJ, Sorlie PD, Arias E: A further study of life expectancy by socioeconomic factors in the National Longitudinal Mortality Study. Ethn Dis 2003, 13:240-247.

39. Arias E: United States life tables, 2004. Natl Vital Stat Rep 2007, 56:1-39.

40. U.S.Census Bureau: Population Estimates, Race/ethnicity. 2010, Accessed from http://www.census.gov/popest/race.html. 
41. Kosoy R, Nassir R, Tian C, White PA, Butler LM, Silva G, et al: Ancestry informative marker sets for determining continental origin and admixture proportions in common populations in America. Hum Mutat 2009, 30:69-78

42. stro-Bisol G, Maviglia R, Caglia A, Boschi I, Spedini G, Pascali V, et al:

Estimating European admixture in African Americans by using

microsatellites and a microsatellite haplotype (CD4/Alu). Hum Genet 1999 104:149-157.

\section{Pre-publication history}

The pre-publication history for this paper can be accessed here:

http://www.biomedcentral.com/1471-2458/12/119/prepub

doi:10.1186/1471-2458-12-119

Cite this article as: Pasipanodya et al: Non-hispanic whites have higher risk for pulmonary impairment from pulmonary tuberculosis. BMC Public Health 2012 12:119.

Submit your next manuscript to BioMed Central and take full advantage of:

- Convenient online submission

- Thorough peer review

- No space constraints or color figure charges

- Immediate publication on acceptance

- Inclusion in PubMed, CAS, Scopus and Google Scholar

- Research which is freely available for redistribution

Submit your manuscript at www.biomedcentral.com/submit 